\title{
NOTAS SOBRE EL GÉNERO POA EN LA PENÍNSULA IBÉRICA*
}

\author{
A. M. Hernández CARdona**
}

\section{RESUMEN}

Se relacionan y comentan las especies del género Poa en la Península Ibérica. Se hace una nueva combinación: $P$. trivialis L. subsp. feratiana (Boiss. et Reuter) A. M. Hernández.

\section{SUMMARY}

An outline of species of genus Poa in Iberian Peninsule is given. A new combination is made: $P$. trivialis L. subsp. feratiana (Boiss. et Reuter) A. M. Hernández.

En estas notas se tratan escuetamente diversas cuestiones de interés sobre las especies del género Poa en la Península Ibérica, tema que, como tesis doctoral, está estudiando el autor, bajo la dirección del Prof. Dr. P. Montserrat, del Centro Pirenaico de Biología Experimental, de Jaca.

\section{Sección OCHLOPOA}

\section{P. annua L.}

Común en toda la Península. Existen diversos taxones subespecíficos, en general poco estudiados. En las regiones húmedas predomina la subsp. o var. annua, y en las secas la var. lanuginosa Sennen (=subsp. pilantha (Ronniger) H. Scholz), caracterizada por la gran pelosidad de la lema. El origen probable de $P$. annua es como alopoliploide de $P$. infirma con

$\left(^{*}\right)$ Comunicación presentada en el Simposio Conmemorativo del Centenario de Lagasca, Departamento de Botánica, Universidad de Sevilla, 30 septiembre - 2 octubre 1976.

(**) Laboratorio de Botánica, Colegio Universitario de Málaga. 
$P$. supina, y uno de sus centros de formación cabe situarlo en las montañas hispánicas y norteafricanas. Su dispersión cosmopolita ha sido relativamente reciente.

\section{P. infirma Kunth}

Se distingue claramente de $P$. апnua por los siguientes caracteres: flores espaciadas, flor terminal igual o un poco más larga que su pedúnculo, ramas de la panícula erguidas y, sobre todo, anteras mucho más cortas, de 0,2 a $0,4 \mathrm{~mm}$ de longitud. Es una especie mucho más frecuente de lo que se creía. Se halla en toda la Península Ibérica, aunque escasea en la parte norte.

\section{P. supina Schrader}

Fácil de diferenciar de $P$. annua por ser perennante y también por sus ramas inferiores típicamente dirigidas hacia abajo, por sus tonalidades purpúreas y por sus anteras de 6 a 8 veces más largas que anchas. Es una planta ordinariamente de montaña, propia de lugares encharcados o muy húmedos. Relativamente frecuente en los Pirineos, se encuentra también en las montañas peninsulares más altas: Cordillera Cantábrica, Macizo Galaico-duriense, Sistema Central, Serra de Estrela incluida, y Sierra Nevada.

\section{P. maroccana Nannfeldt}

Taxon descubierto en España en 1967 por el Prof. Dr. H. Scholz, del Botanischen Garten und Museum Berlin-Dahlem, sobre material del Jardín Botánico de Madrid procedente de Jerez y Cartagena (MA 11 141, 156 755). Es un autopoliploide de $P$. infirma. Morfológicamente es muy difícil distinguirlo de $P$. annua var. lanuginosa (=subsp. pilantha). Tal vez sea un taxon no raro en la Península Ibérica, pero su detección es prácticamente imposible con criterios morfológicos sencillos.

Sección COENOPOA

P. trivialis L. subsp. trivialis

Abundante en toda la Península Ibérica. Hay formas típicas y formas de tránsito con la subsp. sylvicola y con la subsp. feratiana.

P. trivialis L. subsp. sylvicola (Guss.) Lindb. fil.

Es reconocible por sus raíces moniliformes y por su panícula estrecha. Es frecuente en el Alentejo, Extremadura, Andalucía y Baleares. Este taxon tiene su óptimo en la región mediterránea oriental. 
P. trivialis L. subsp. feratiana (Boiss. et Reuter) A. M. Hernández nova comb. (=P. feratiana Boiss. et Reuter, Pugillus, 128 [1852]).

Se distingue de la subsp. trivialis por los siguientes caracteres: espículas todas con dos flores, verticilos inferiores de la panícula con (1)2-3(5) ramas, hojas de anchura menor (menos de $3 \mathrm{~mm}$ ), panícula oblonga y no piramidal, y ramas de la panícula más finas y algo alabeadas. Tras examinar detenidamente el tipo ( $G$, herb. BOISSIER), se puede afirmar que algunos de los caracteres que se le habían atribuido no son tales. Así, la lema tiene 5 nervios y no 3, lo que ocurre es que los dos marginales suelen estar muy próximos al borde. Por otra parte, la lema sí que es lanada en la base, aunque mucho menos que en la subsp. trivialis; esto ya se ponía de manifiesto en la descripción original ("parce lanatis"), que fue mal interpretada por autores posteriores. Vive en sitios muy sombríos y húmedos, pero no encharcados, de condiciones climáticas de tipo atlántico. Se encuentra en el norte y otros puntos de Portugal, en Galicia, región donde es más abundante, en el litoral cantábrico, en los Pirineos, sobre todo en valles de la vertiente septentrional, $\mathrm{y}$ en algunas zonas húmedas de Cataluña.

\section{P. flaccidula Boiss. et Reuter}

A menudo confundida con $P$. trivialis, de la que se distingue claramente por los siguientes caracteres: ramas inferiores geminadas, espículas agrupadas en el extremo de las ramas, flores habitualmente en número de tres por espícula y lemas seríceas. Es un endemismo ibero-baleárico-mauritánico, que crece en terrenos pedregosos, aunque no excesivamente secos, muchas veces al pie de peñascales. Se extienden por las montañas calizas del sur y este peninsular, desde la Serranía de Grazalema hasta los Prepirineos, de la Serra de Tramuntana en Mallorca, y del norte de África, pero siempre en zonas cacuminales, sin descender nunca a nivel del mar. Recientemente, revisando material del Instituto Botánico de Barcelona, el autor la ha descubierto en el Principado de Cataluña (BC 103 754, 103755 , 599 148, 599 270, 599 271, 599 273). En las islas Baleares fue encontrada por PORTA, quien la describió en 1895 como P. balearica, nombre que por el principio de prioridad ha de pasar a la sinonimia. Hay bastantes testimonios de herbario de $P$. flaccidula recolectados en Mallorca (BC 106810 , 137 144, 137213 ; MA 11 481; etc.), los cuales han sido debidamente comprobados o enmendados. 
Sección POA

\section{P. pratensis L.}

Planta pratícola importante. Es relativamente común en la Iberia húmeda, pero escasea hasta desaparecer en el sur de la Península. Hay diversas razas, generalmente cromosómicas, entre las cuales cabe citar la montícola subsp. legionensis Laínz, propia de los montes cántabro-leoneses.

\section{P. angustifolia L.}

Del grupo de $P$. pratensis, se distingue de ella por la lígula no decurrente, porque la rama mayor del verticilo inferior es menor que un tercio de la longitud de la panícula, y por ser las hojas de los brotes estrechas, enrolladas y casi tan altas como el tallo. Es casi tan frecuente como P. pratensis, siendo su área de distribución un poco más amplia, llegando hasta las Baleares, aunque restringida a los sitios más húmedos de la Serra de Tramuntana.

\section{P. subcaerulea Sm.}

Aunque no se ha demostrado todavía su existencia en la Península Ibérica, es posible que se halle en Galicia y el norte de Portugal.

\section{Sección CENISIA}

\section{P. cenisia All.}

Planta rizomatosa y glauca. Vive en cascajares y pedregales de alta montaña. Se halla en los Pirineos, Cordillera Cantábrica y Sistema Ibérico septentrional. Han sido citadas la subsp. sardoa Schmid $(=P$. fontquerii Br.-Bl.) y la subsp. cenisia.

Sección HOMALOPOA

\section{P. chaixii Vill.}

Fácilmente identificable por sus hojas anchas (5 a $10 \mathrm{~mm}$ ) y por su tallo robusto y comprimido. Propia de bosques y prados de montaña. Se encuentra en los Pirineos, Cordillera Cantábrica, montañas galaico-leonesas y norte del Sistema Ibérico (Sierra de la Hez). $P$. commutata Roemer et Schultes, descrita de la Cordillera Cantábrica, corresponde casi con seguridad a esta especie. 


\section{Sección OREINOS}

\section{P. laxa Haenke}

Los principales caracteres diferenciales frente a $P$. minor son los siguientes: ramas de la panícula surcadas, de 3 a 4 flores por espícula, glumas mucho más largas que la mitad de la longitud de la espícula, y cariopsis maduras no adnadas a la pálea. Es silicícola. Se halla en los Pirineos orientales y centrales, desapareciendo en los occidentales. Reaparece en la Cordillera Cantábrica y en la Sierra Nevada.

\section{P. minor Gaudin}

Algunos de los caracteres que la distinguen de $P$. laxa son estos: ramas de la panícula lisas y capilares, de 4 a 6 flores por espícula, glumas iguales o menores que la mitad de la longitud de la espícula, y cariopsis maduras adnadas a la pálea. Es calcícola. Se encuentra en los Pirineos, abundante en los occidentales y ausente o rara en los orientales, y también en la Cordillera Cantábrica. Existe asimismo en la Sierra Nevada, representada por su subsp. nevadensis, descrita por NANNFELD en 1937, y de la cual hay numerosos testimonios de herbario (BCF 1 767, 1769 ; GDA; MA 11379, 11385 ; MAF 28595 ; etc.). Este taxon de Sierra Nevada claramente corresponde a $P$. minor, aunque quizá sea excesivo el rango de subespecie, por lo cual se propone aquí provisionalmente la categoría de variedad.

\section{Sección STENOPOA}

\section{P. nemoralis L.}

Típicamente de bosque, hay también varios táxones propios de roquedas, por lo general poco estudiados. Escasea en el sur peninsular.

\section{P. glauca Vahl}

Aunque repetidamente citada de los Pirineos, el autor no la ha visto ni en montaña ni en material de herbario, correspondiendo los pliegos examinados que tenían este nombre a otras especies. Se puede casi asegurar su inexistencia, por lo menos en la vertiente española de los Pirineos. Muchas de las citas bibliográficas se refieren a la var. glauca (DC.) de $P$. nemoralis. 


\section{P. bulbosa L.}

Es inconfundible por su bulbo basal. Es frecuente en toda la Península Ibérica, normal o en estado vivíparo. No cabe hablar de una subsp. vivipara, puesto que la viviparidad es fisiológica. Está asociada al pastoreo, especialmente ovino, y es típica de los majadales.

\section{P. ligulata Boiss.}

Es fácilmente reconocible por sus lígulas largas (de 3 a $5 \mathrm{~mm}$ ) y blanquecinas. Especie endémica ibero-mauritánica, se extiende por las montañas del arco hespérico, desde la Serranía de Grazalema hasta las montañas gallegas orientales: Sistema Penibético, Sistema Ibérico y estribaciones y Cordillera Cantábrica, pero no alcanza los Pirineos ni se interna en el Sistema Central más allá de Somosierra. Está ligada a la crioturbación.

\section{P. alpina L.}

Planta abundante en los pisos alpinos de casi todos los principales sistemas montañosos: Pirineos, Cordillera Cantábrica y estribaciones, Sistema Central hasta la Sierra de Béjar, y partes del Sistema Ibérico. No existe en Sierra Nevada, ni en otras montañas del Sistema Penibético, donde erróneamente había sido citada, confundida con formas laxas de $P$. ligulata. El grupo de $P$. alpina es realmente complicado y presenta todavía muchos problemas, no solamente en la Península Ibérica, sino también en el resto de la región holártica. Dentro de este grupo están las dos especies que a continuación se reseñan.

\section{P. molinerii Balbis}

Se diferencia de $P$. alpina por su color glauco y por sus hojas más cortas. Muchos ejemplares de los Pirineos, especialmente de los centrales y occidentales, y aun algunos de la Cordillera Cantábrica, pueden ser asignados a esta especie.

\section{P. badensis Haenke ex Willd.}

Se caracteriza por las hojas cortas y con margen cartilaginoso, y por las lígulas largas. Hay todo un tránsito con la llamada subsp. brevifolia de $P$. alpina. Se encuentra en los Pirineos y posiblemente en la Cordillera Cantábrica. 
Finalmente cabe hablar de $P$. violacea, que actualmente se adscribe al género Bellardiochloa.

Bellardiochloa violacea (Bellardi) Chiov.

Presenta características morfológicas que la sitúan a medio camino de Poa y Festuca. Las glumas y lemas carinadas, y la forma del hilo de la cariopsis, la aproximan a Poa, mientras que las lemas apiculadas y la anatomía foliar, la acercan a Festuca. Crece en prados y a veces en pedregales, del piso alpino. Existe únicamente en los Pirineos y la Cordillera Cantábrica. Entre los sinónimos comúnmente usados en floras antiguas, están $P$. setifolia Zett., Festuca pilosa Haller fil. y F. rhaetica Suter.

Agradecimlentos: A los Profs. Drs. Montserrat, Edmondson, KerguÉlen y Vivant, por sus amables indicaciones.

(Recibido el 20 de octubre de 1976) 